\title{
Integrated management of water resources demand and supply in irrigated agriculture from plot to regional scale
}

\author{
Niels Schütze and Michael Wagner \\ Institute of Hydrology and Meteorology, TU Dresden, 01279 Dresden, Germany \\ Correspondence to: Niels Schütze (niels.schuetze@tu-dresden.de) \\ Published: 12 May 2016
}

\begin{abstract}
Growing water scarcity in agriculture is an increasing problem in future in many regions of the world. Recent trends of weather extremes in Saxony, Germany also enhance drought risks for agricultural production. In addition, signals of longer and more intense drought conditions during the vegetation period can be found in future regional climate scenarios for Saxony. However, those climate predictions are associated with high uncertainty and therefore, e.g. stochastic methods are required to analyze the impact of changing climate patterns on future crop water requirements and water availability. For assessing irrigation as a measure to increase agricultural water security a generalized stochastic approach for a spatial distributed estimation of future irrigation water demand is proposed, which ensures safe yields and a high water productivity at the same time. The developed concept of stochastic crop water production functions (SCWPF) can serve as a central decision support tool for both, (i) a cost benefit analysis of farm irrigation modernization on a local scale and (ii) a regional water demand management using a multi-scale approach for modeling and implementation. The new approach is applied using the example of a case study in Saxony, which is dealing with the sustainable management of future irrigation water demands and its implementation.
\end{abstract}

\section{Introduction}

Arid and semi-arid areas that are intensively used for agriculture, are facing water shortage which is often intensified by an overexploitation of existing water resources. Accordingly, they show an increased sensitivity to water stress and a high vulnerability that can only be reduced by a highly efficient and foresighted water resource management practices. Same observations are less pronounced for Saxony, but signals of longer and more intense drought conditions during the vegetation period can be found in future regional climate scenarios and irrigation may become relevant as a measure to mitigate drought stress for agricultural crops in future. For assessing irrigation as a measure to increase agricu-ltural water security a generalized stochastic approach for a spatial distributed estimation of future irrigation water demand is proposed in this contribution, which ensures safe yields and a high water productivity at the same time. Recent studies, e.g. (Semenov, 2007; Brumbelow and Georgakakos, 2007), try to analyze possible impacts of climate variability and cli- mate change on agriculture, based on process-based simulation models.

Only, a few papers (Brumbelow and Georgakakos, 2007; Schütze and Schmitz, 2010) focus on irrigation management under limited water availability which requires a deficit irrigation strategy with the target to achieve water productivity (WP) rather than maximum yield. The improvement of WP needs a good quantitative understanding of the relationship between irrigation practices and grain yield, i.e. the crop water production function (CWPF). With this knowledge, the value of each unit of water applied to a field can be estimated and compared with alternative uses within and beyond the agricultural sector. However, the estimation of WP for limited water availability is difficult on a regional level because the performance of irrigation systems depend on a number of factors such as climate conditions, grown crops, soil hydraulic characteristics and used irrigation systems. In addition, the stochastic properties of the relevant climate factors (e.g. precipitation and temperature) and of the soil properties have to be considered in a risk-based regional water manage- 


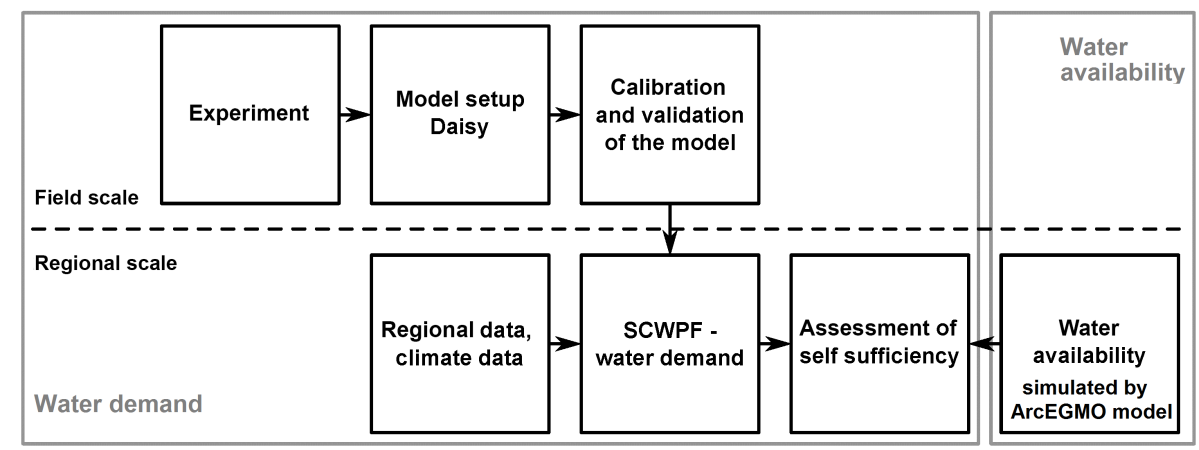

Figure 1. Work flow for estimating regional irrigation water demand from field scale simulations and regional water availability using the ArcEGMO model.

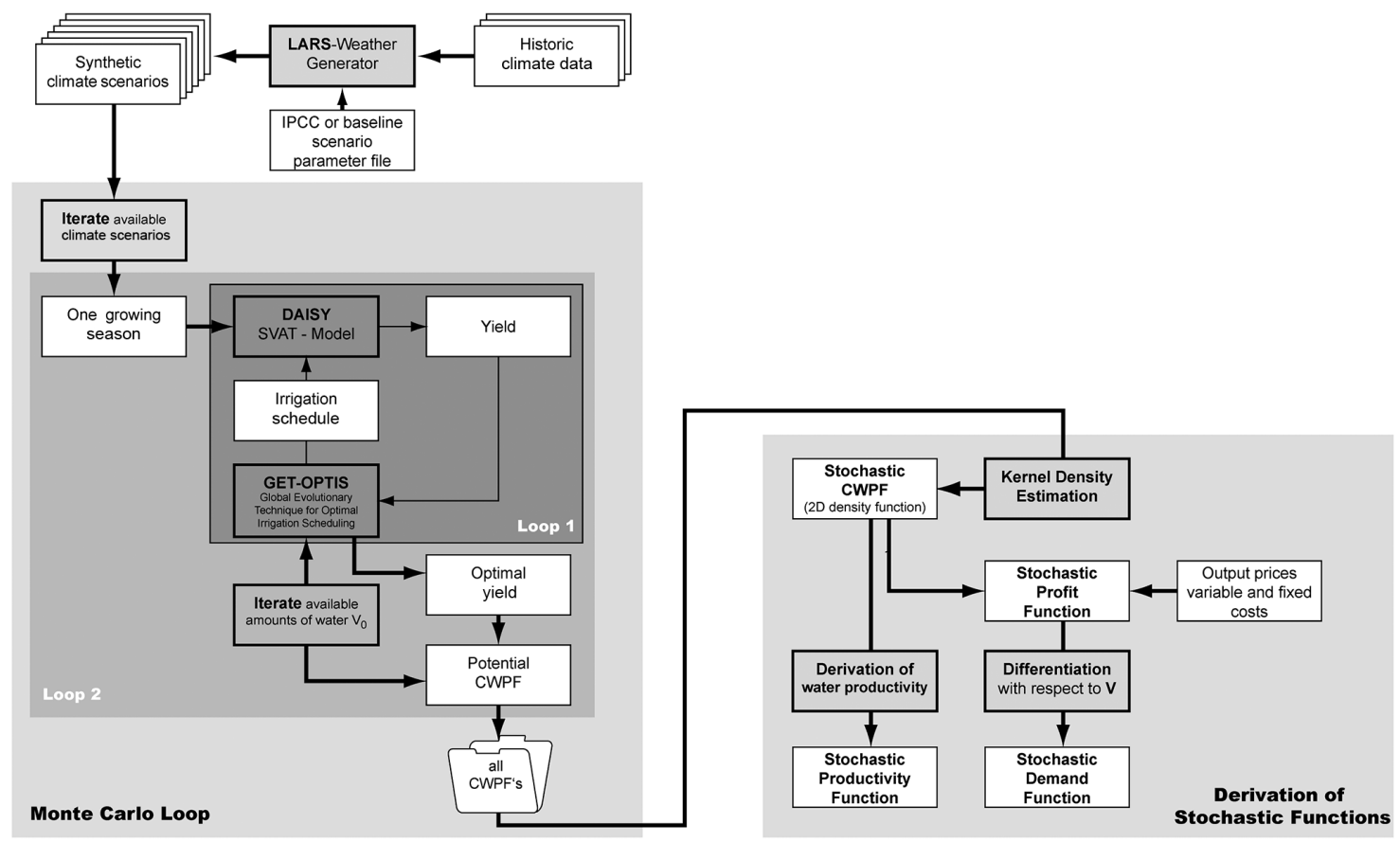

Figure 2. Layout of the stochastic framework for generating stochastic crop production functions on field scale.

ment. Thus, the objective of this study is to demonstrate in a generic framework how stochastic crop water production functions (SCWPF) generated on a field scale can serve as a tool for estimating regional water demand using an upscaling approach.

\section{Overview of the stochastic framework}

The work flow for estimating regional irrigation water demand from field scale experiments and simulations, shown in Fig. 1, was developed and implemented in the project "SAPHIR" (Schütze et al., 2016).

Figure 1 shows the work flow of all methods, grouped in field and regional scale. Irrigation experiments were conducted with several crops at three experimental sites in Ger- many. Model parameters were derived based on field irrigation experiments using the crop soil-vegetation-atmospheretransfer (SVAT) model Daisy (Abrahamsen and Hansen, 2000). The crop model parameters and the stochastic relationship between irrigated water and crop yield (SCWPF stochastic crop water production function) served as a basis for regional crop model simulations (see Fig. 2). The stochastic approach allows direct information of uncertainty. The corresponding crop water demand and the derived water availability result in the degree of local water self-sufficiency that was estimated for mid and northern Saxony in a real case application. For the estimation of available water resources under different climate change scenarios the hydrological model ArcEGMO was used (Schwarze et al., 2016). 


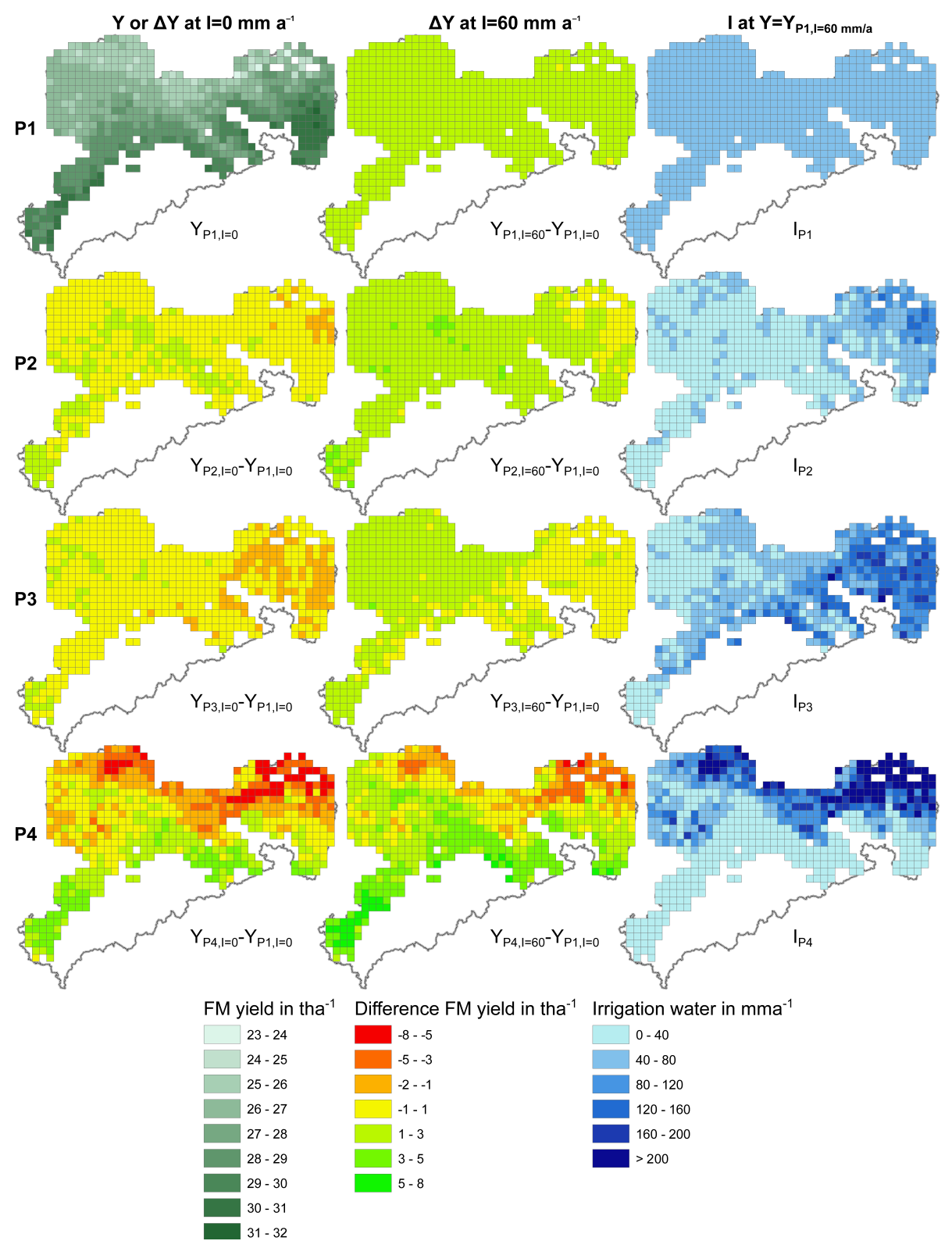

Figure 3. 1st column: regional fresh matter bean yield (1st row) and yield differences between future time periods (2nd to 4th row) with no irrigation. 2nd column: fresh matter yield differences for each time period from no irrigation to $60 \mathrm{~mm}$ per year irrigation. $3 \mathrm{rd}$ column: irrigated water amount, if crop yield shall not decrease under yield level of period P1. All results are averaged over all soils in each grid cell and medians of corresponding SCWPF (for details see Wagner et al., 2015).

The generic framework for the generation of SCWPF's comprises of an optimizer and a Monte Carlo sampler. For the optimizer two components are required to achieve reliable CWPFs for one realisation of the climate conditions (see Fig. 2, loop 1): an irrigation scheduling optimizer and a simulator of plant growth and water transport. The objective of the optimization is to maximize yield for a given climate realisation and a given amount of water for irrigation during the growing season.
Within a second loop which iterates over a range of given water volumes, a complete CWPF can be constructed.

In the third loop a required number of CWPFs is generated in order to accurately compute the statistical characteristics of the random sample of CWPFs in a non-parametric way, i.e. the resulting SCWPF is an empirical probability function.

To be useful for Monte Carlo simulations, the irrigation scheduling optimizer and the simulation model should be highly efficient and effective in finding the global maximum yield in order to generate a SCWPF within an acceptable 


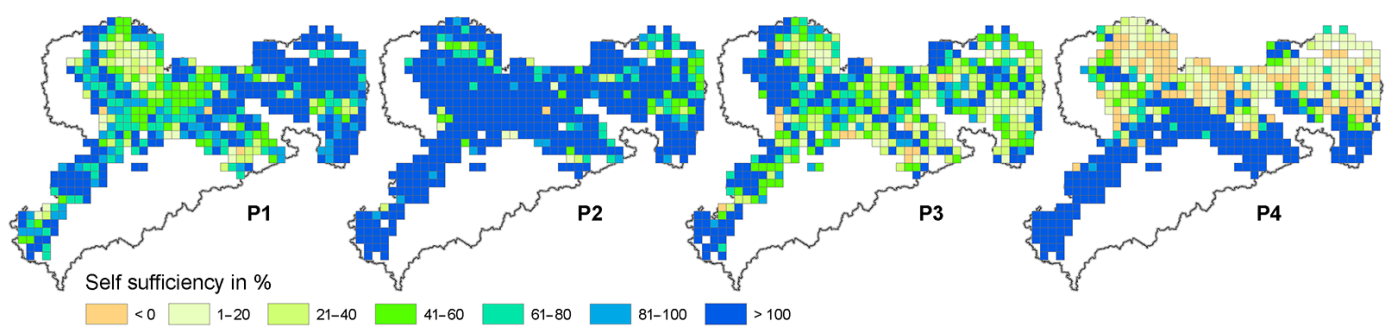

Figure 4. Predicted water self-sufficiency for common bean in relevant regions of Saxony. The water demand results from the same crop yield in all time periods as in P1 with Irrigation $=60 \mathrm{~mm}$ per year. The available water covers $50 \%$ of groundwater recharge plus surface water. All results are averaged over soils in each grid cell and medians of corresponding SCWPF (for details see Wagner et al., 2015).

computation time. Finally, the generated empirical probability function SCWPF is converted into a continuously differentiable density function for the calculation of derivatives such as productivity, profit and demand function.

\section{Results}

For a regional analysis of future development of irrigation water demand and local self-sufficiency in Saxony the spatial resolution for estimating SCWPF depending on local climate conditions, grown crops, soil hydraulic characteristics and used irrigation systems is 5 by $5 \mathrm{~km}$.

For statistical analysis, we refer to 30 -year periods. 19611990 (P1) is assumed as recent climate, 1991-2020 (P2) is the actual situation, 2021-2050 (P3) is the near future and 2071-2100 (P4) the far future projection. For the regional analysis climate data from the statistical regional climate model WEREX $\mathrm{V}$ was used.

Figure 3 shows the regional development for beans in different temporal periods P1 to P4. The upper left picture displays the non-irrigated regional crop yield in P1. A decrease from south to north based on drier climate and a higher sand fraction of the upper soil is apparent. The maps illustrates developments in crop yield for P2 to P4 using the differences in non-irrigated crop yield for P2 to P4. Especially the north eastern part of Saxony suffers from minor yield decreases in $\mathrm{P} 2$ and P3 whereas in P4 most parts in the area of investigation show a significant decrease for larger part of the regions. Irrigation can be an appropriate measure to stabilize yields. This becomes apparent from the last column where the required irrigation water volume is shown for periods $\mathrm{P} 2$ to $\mathrm{P} 4$ which must be applied in order to achieve the crop yield of period P1. In P2 only few regions in the north east have a higher irrigation demand. However, in period $\mathrm{P} 4$ with a significant higher rate of evapotranspiration significant more irrigation water is required for the most regions in order to secure crop yield.

Figure 4 maps self-sufficiency in relevant regions of Saxony where agriculture is relevant. For periods P1 and P2 small deficits of self-sufficiency can be observed in mid northern Saxony.
In contrast, period P4 shows an even lower degree of selfsufficiency in the northern part, although a number of blue spots are indicating larger water reservoirs which provide additional water resources for irrigation.

\section{Conclusions}

In this study, a new multi-scale approach for integrated modeling and management of irrigation systems was developed, implemented and tested at a regional scale. The use of a tailor-made evolutionary optimization algorithm for optimal irrigation management with limited water supply allows the estimation of the potential performance (e.g. irrigation efficiency, economic productivity and price elasticity of water demand) of agro-hydrological units, characterized for example, by its soil, grown crops and irrigation method. To take climate variability into account the agronomic response to different levels of water application is represented by stochastic crop water production functions (SCWPF). For the region of Saxony preliminary results show that primarily the northern part of Saxony is particular affected by the drier projected future climate which can partly be compensated by irrigation measures using local water resources. The proposed multi-scale approach for integrated modeling and management of irrigation systems can easily be extended to introduce other components in the regional water management, e.g. technical systems for water storage and distribution (Müller and Schütze, 2013). Furthermore, the developed multi-scale approach is transferable to different climate conditions, e.g. it is implemented and validated for the arid region of Oman (Schütze et al., 2012).

Acknowledgements. These investigations are part of the research project "SAPHIR - Saxonian Platform for High Performance Irrigation" funded by the EU ESF "Nachwuchsforschergruppen" program under grant no. 100098204. 


\section{References}

Abrahamsen, P. and Hansen, S.: Daisy: an open soil-cropatmosphere system model, Environ. Modell. Softw., 15, 313$330,2000$.

Brumbelow, K. and Georgakakos, A.: Consideration of climate variability and change in agricultural water resources planning, $\mathrm{J}$. Water Res. Pl.-ASCE, 133, 275-285, 2007.

Müller, R. and Schütze, N.: Improving the future performance and reliability of multi- reservoir systems by multi-objective optimization, in: IAHS-IAPSO-IASPEI Assembly, edited by: Schumann, A. H. and Belyaev, V., Gothenburg, Sweden, vol. 362 of Red Book, 24-32, 2013.

Schütze, N. and Schmitz, G. H.: OCCASION: A new Planning Tool for Optimal Climate Change Adaption Strategies in Irrigation, J. Irrig. Drain. E.-ASCE, 136, 836-846, doi:10.1061/(ASCE)IR.1943-4774.0000266, 2010.

Schütze, N., Kloss, S., Lennartz, F., Al Bakri, A., and Schmitz, G. H.: Optimal planning and operation of irrigation systems under water resource constraints in Oman considering climatic uncertainty, Environmental Earth Sciences, 65, 1511-1521, 2012.
Schütze, N., Stange, P., Griessbach, U., Röhm, P., and Wagner, M.: Integrated modelling and optimisation of irrigation systems at the field and catchment scale with limited water resources, Hydrologie und Wasserbewirtschaftung, 60, 7-21, 2016.

Schwarze, R., Dröge, W., Wagner, M., Spitzer, S., Maleska, V., and Kuhn, K.: Research on possible impacts of climate change on the water balance in Saxony - approach, analysis of the status quo, data and parameter model, model test, Hydrologie und Wasserbewirtschaftung, 60, 53-71, 2016.

Semenov, M. A.: Development of high-resolution UKCIP02-based climate change scenarios in the UK, Agr. Forest Meteorol., 144, 127-138, 2007.

Wagner, M., Seidel, S. J., and Schütze, N.: Irrigation water demand of common bean on field and regional scale under varying climatic conditions, Meteorol. Z., doi:10.1127/metz/2015/0698, 2015. 